\title{
Social Media and Mental Health: Reviewing Effects on Eudaimonic Well-Being
}

\author{
Adrian Meier, $\mathrm{PhD}$ \\ School of Business, Economics and Society \\ Friedrich Alexander University of Erlangen-Nuremberg, Germany \\ Leonard Reinecke, $\mathrm{PhD}$ \\ Department of Communication \\ Johannes Gutenberg University Mainz, Germany
}

This is a preprint of a chapter submitted to the upcoming handbook

Our Online Emotional Selves: The Link Between Digital Media and Emotional Experience edited by Robin L. Nabi \& Jessica Gall Myrick.

\section{Corresponding author:}

Dr. Adrian Meier

Assistant Professor for Communication Science

School of Business, Economics and Society

Friedrich Alexander University of Erlangen-Nuremberg

Findelgasse 7/9

90402 Nuremberg

Germany

Email: adrian.meier@ fau.de 


\begin{abstract}
Do social media affect users' mental health and well-being? By now, considerable research has addressed this highly contested question. Prior studies have investigated the effects of social media use on hedonic well-being (e.g., affect and life satisfaction), psychopathology (e.g., depressive or anxiety symptoms), or psychosocial risk/resilience factors (e.g., loneliness, stress, self-esteem). Yet, public concern over social media effects often centers on more long-term negative outcomes, which may be better captured by indicators of eudaimonic well-being. Indeed, neglecting the eudaimonic side of well-being may have introduced outcome omission bias, since eudaimonia is both conceptually and empirically distinct from other dimensions of mental health and may be uniquely affected by social media use. Specifically, psychology currently theorizes eudaimonic well-being to be best represented by the experiences of (a) meaningfulness, (b) authenticity, and (c) selfactualization. A research synthesis of how social media use relates to these core indicators of eudaimonia is currently missing, however. We thus present a first narrative review that synthesizes both theoretical and empirical links between three key social media uses (i.e., active, passive, and "screen time") and eudaimonic well-being. The synthesis shows that while there are indeed several plausible theoretical links, the evidence is too scarce and inconsistent to allow definitive conclusions at this time. We instead give recommendations for how the field can close important gaps by investigating whether social media afford or constrain opportunities to find meaning, live authentically, and grow as a person.
\end{abstract}

Keywords: social media, mental health, well-being, narrative review, active use, passive use, screen time 


\section{Social Media and Mental Health: Reviewing Effects on Eudaimonic Well-Being}

Since the advent of social and mobile media, researchers and the public have fervidly debated their impact on users' mental health and well-being, particularly adolescents and young adults (e.g., Orben, 2020; Twenge, 2019; Valkenburg \& Peter, 2011). Much has been done to integrate this highly fragmented and interdisciplinary field structurally, conceptually, and empirically in recent years (Appel et al., 2020; Meier, Domahidi, \& Günther, 2020; Meier \& Reinecke, 2020; Orben, 2020). Most of this research has understood mental health as either subjective well-being, psychopathology, or some psychosocial risk/resilience factor. Yet, public discourse typically assumes that new media technologies will "take people away from living a good and meaningful life" (Rigby \& Ryan, 2017, p. 44), which is not fully captured by these mental health indicators.

Indeed, in a prior review, we found that research investigating social media effects on such eudaimonic well-being (EWB) is scarce, with existing studies currently lacking synthesis (Meier \& Reinecke, 2020). EWB, often contrasted with hedonic or subjective well-being, refers to experiences of meaning, authenticity, and the realization of one's true and best self. It thus represents a distinct dimension of "the good life" (Huta \& Waterman, 2014; Martela \& Sheldon, 2019). EWB may be uniquely affected by social media use, as suggested by, for instance, proponents of "digital detox" and "digital well-being" self-help literature (Syvertsen \& Enli, 2019). Yet, scientific evidence on this appears fragmented. Accordingly, we can obtain a more complete and deeper understanding of social media's mental health impacts by considering the eudaimonic side of well-being.

In this chapter, we thus review the literature on social media and mental health with a particular emphasis on eudaimonic well-being. In the following, we first outline how EWB fits into the larger mental health context and compares to hedonic well-being. Starting from a broad overview that discusses how social media are linked to key indicators of mental health (i.e., hedonic well-being, psychopathology, and psychosocial risk/resilience factors), we then 
integrate the fragmented theoretical and empirical links between social media and EWB. This is done with a focus on the three most agreed-upon EWB indicators-meaningfulness, authenticity, and self-actualization (Huta \& Waterman, 2014). We structure our theory and evidence review along a popular distinction that juxtaposes active and passive social media uses (Verduyn et al., 2017) and complement this with the "screen time" approach, that is, research agnostic to how social media are used (Orben, 2020b; Twenge, 2019). The chapter thus contributes to the larger discourse on digital media's emotional and mental health effects by highlighting EWB as a so far understudied outcome that shows complex connections to both social media engagement and the emotional side of well-being.

\section{Mental Health and Well-Being}

Mental health has become a key outcome in the media effects literature over the last decades, particularly concerning computer-mediated communication (CMC), social media, and mobile devices (Meier, Domahidi, \& Günther, 2020). Broadly defined, mental health refers to "a state of well-being in which every individual realizes his or her own potential, can cope with the normal stresses of life, can work productively and fruitfully, and is able to make a contribution to her or his community" (World Health Organization, 2005, p. 2). The concept thus goes significantly beyond the absence of mental illness or ill-being; rather, it emphasizes a fully functioning person that experiences well-being - a positive, surplus state of health.

Research on social and mobile media effects, however, has assessed a plethora of disconnected and therefore difficult to integrate indicators of mental health. Our recent reviews of this field found that studies typically operationalize mental health with a mix of psychopathology, psychological well-being, or some psychosocial risk/resilience indicators (Meier, Domahidi, \& Günther, 2020; Meier \& Reinecke, 2020), underlining the need for further conceptual clarification. Psychopathology refers to "any pattern of behavior-broadly defined to include actions, emotions, motivations, and cognitive and regulatory processesthat causes personal distress or impairs significant life functions, such as social relationships, 
education, work, and health maintenance" (Lahey et al., 2017, p. 143). Well-being in general describes "how well individuals are doing in life, including social, health, material, and subjective dimensions of well-being” (Diener et al., 2018, p. 3), whereas psychological wellbeing more narrowly focusses on "optimal psychological functioning and experience" (Ryan \& Deci, 2001, p. 142). Given the goals of the present chapter, we turn our attention more closely to psychological well-being (henceforth simply: well-being).

\section{Hedonic and Eudaimonic Well-Being}

Based on a selective account of ancient Greek philosophy (Crisp, 2013), Positive Psychology typically distinguishes two overarching perspectives, namely hedonic and eudaimonic well-being (e.g., Huta \& Waterman, 2014; Martela \& Sheldon, 2019; Ryan \& Deci, 2001; Ryff, 1989). The key difference between the two is disagreement about what represents the most relevant markers of "the good life" (see Kashdan et al., 2008, for extended discussion).

Hedonic well-being (HWB) research typically argues that well-being should be defined purely by the subjective experience of pleasure and contentment (Huta \& Waterman, 2014; Martela \& Sheldon, 2019). The most widely employed operationalization is subjective well-being (Diener, 1984; Diener et al., 2018), which consists of two interrelated components: affective well-being (high positive and low negative affect) and cognitive well-being (satisfaction with life overall and major life domains). Essentially, in this tradition, an individual is argued to be well if they frequently experience positive affect, only occasionally experience negative affect, and are satisfied with life and its major domains (Diener et al., 2018).

Eudaimonic well-being (EWB) proposes that being well depends on the realization of a "true self" (i.e., the daímōn), and thus on more than just pleasure (affective well-being) and contentment (cognitive well-being). Yet, there is still much disagreement about how exactly eudaimonic well-being should be conceptually and operationally defined (Kashdan et al., 
2008). For instance, a recent review identified at least 45 measures that tap into 63 different supposedly eudaimonic concepts (Martela \& Sheldon, 2019). However, when tacking stock of various researchers' conceptualizations of EWB systematically (see Huta \& Waterman, 2014), EWB is most often understood and measured as (a) meaningfulness, (b) authenticity, and (c) self-actualization. While there are several alternative approaches to EWB (e.g., Ryff, 1989; Martela \& Sheldon, 2019), research on social media effects may, for now, benefit from focusing on these three core EWB indicators. Hence, EWB is here understood as frequently experiencing meaning and authenticity as well as actualizing one's true self.

There are at least two main reasons for why EWB now often complements HWB in both theory and research (Huta \& Waterman, 2014; Martela \& Sheldon, 2019). First, in its most radical version, the hedonic view essentially argues that anything goes - if an action increases one's momentary pleasure and contentment, or decreases pain, it is seen as contributing to the good life (Crisp, 2013). Consequently, research on hedonic well-being is decidedly agnostic about the "ingredients" of a good life (Diener et al., 2018). Yet, there seem to be certain ingredients (i.e., experiences) beyond pleasure and contentment that have been repeatedly associated with a life well lived, especially meaningfulness, authenticity, and selfactualization (Huta \& Waterman, 2014). Moreover, negative experiences, such as setbacks in one's work or relationships, may contribute to EWB by increasing comprehension of one's personal development (Tov \& Lee, 2016; Vohs et al., 2019). Crucially, these negative experiences would be overlooked by a purely hedonic perspective. Second, there are countless examples for when maximizing pleasure is problematic (e.g., when regularly taking crystal meth) or even morally reprehensible (e.g., when experiencing pleasure from hurting others). Eudaimonic philosophy is thus, among other reasons, a response to the moral ambiguity of the hedonic view, especially to utilitarianism (Crisp, 2013). Together, these two reasons explain why many argue we should consider more than just pleasure and contentment as markers of well-being (Huta \& Waterman, 2014). 


\section{The Interplay Between Hedonic and Eudaimonic Well-Being}

The evidence to date suggests that many HWB and EWB indicators, when averaging them across situational experiences, are moderately to strongly positively correlated (e.g., Cowan, 2019; Huta, 2017). This appears to be true not just for cognitive well-being (i.e., life satisfaction) but also affective well-being, which is a key source of meaning experiences (e.g., King et al., 2016; Tov \& Lee, 2016). Thus, people living a meaningful, authentic, and selfactualized life also experience, on average, more positive than negative emotions as well as high contentment. Yet, at the same time, factor analyses demonstrate that HWB and EWB can be separated not just conceptually but also empirically (e.g., Huta, 2017). Several studies and meta-analyses further reveal diverging correlations of HWB and EWB indicators with individual and cultural factors (e.g., marital status, personality, or individualism) and different trajectories over time (e.g., Anglim et al., 2020; Burns \& Ma, 2015; Cowan, 2019).

The distinctness of HWB and EWB is particularly evident from their temporal interrelation: experiencing HWB in the moment is not necessarily associated with increased short- or long-term EWB, and vice versa (e.g., Burns \& Ma, 2015). This dissociation is almost definitional given eudaimonic philosophy is founded upon the critique of activities that only feel good momentarily, but do not contribute to any larger or lasting sense of functioning or flourishing. In addition, certain events and experiences may contribute to EWB, but are negatively related to HWB, particularly to affective well-being. The most important evidence for this comes from research on meaningfulness. For instance, a series of six studies showed that meaningfulness can be separated from satisfaction by their distinct associations with affect (Tov \& Lee, 2016): Whereas satisfaction was related to a dominance of positive over negative affect, meaningfulness was not. The evidence overall supported the notion that (strongly) negative events can contribute to meaning, at least under certain boundary conditions, such as resolution and constructive coping. In a recent review, Vohs et al. (2019) thus argued that negative experiences can add to PWB by stimulating cognitive processes that 
help humans "make sense of the world", that is, increase comprehension of one's personal development and life overall. Similar arguments have been made for mixed emotions (e.g., Berrios et al., 2018), especially in the context of eudaimonic entertainment media use (see Oliver \& Raney, this volume). A final intriguing notion is that humans engage in tradeoffs between HWB and EWB (e.g., Abe, 2016), for instance, when prioritizing emotionally negative activities that contribute to long-term personal growth (e.g., strenuous work tasks) over short-term pleasures, as investigated by self-control research (Hofmann et al., 2017).

Overall, the existing research supports the conceptual and empirical distinctness of HWB and EWB and suggests that measuring HWB is insufficient to capture humans' psychological thriving in full. While HWB and EWB are often positively associated when averaging across situations at person-level, they may be dissociated, even negatively related, or "traded" in some situations. This, in turn, suggests that (social) media effects research focusing solely on hedonic outcomes (i.e., affect or satisfaction) may miss important contributions to, or impairments of, mental health. Thus, unique effects of social media may become visible from a eudaimonic point of view.

\section{Social Media and Their Uses}

Having clarified the key outcome of interest, we turn our attention back to the context of interest, social media use. While other media may be relevant for EWB too, we here focus on social media as they (a) have been at the center of the last decade's debate around digital media's mental health effects (e.g., Meier, Domahidi, \& Günther, 2020; Orben, 2020) and (b) limit the potentially relevant phenomena to a reasonable number for this review. Social media are defined as "computer-mediated communication channels that allow users to engage in social interaction with broad and narrow audiences in real time or asynchronously" (Bayer et al., 2020, 10.2). Thus, the defining characteristic of social media is affording human-tohuman interaction through computer-mediated messages, be it via text, voice, images, or videos. This includes social network sites (SNS) such as Facebook, Twitter, or Instagram as 
well as interpersonal social media, particularly messengers such as Facebook Messenger, Instagram Direct, or WhatsApp.

In the literature, three major approaches linking social media use to mental health exist: (1) links requiring active use; (2) links requiring passive use; and (3) links ignoring how social media are used, also termed "screen time". While conceptually and operationally still blurry (Trifiro \& Gerson, 2019), the active-passive distinction is now regularly applied in social media effects research. Based on Verduyn et al. (2017, p. 281), active use is an umbrella term for all "direct exchanges" between users on social media and comprises both masspersonal (e.g., publicly posting content or comments) and interpersonal uses (e.g., sending private messages) (O’Sullivan \& Carr, 2018). Passive use (also coined following, browsing, lurking, monitoring, content consumption, or social surveillance) comprises all forms of merely receiving others' social information and content (e.g., scrolling through the news feed or looking at profiles) without engaging in direct feedback or exchange (e.g., likes, comments). The third approach is evident from numerous studies that investigate entire devices or applications as the main level of analysis (Meier \& Reinecke, 2020), typically in the form of some screen time measure (e.g., Orben, 2020; Twenge, 2019). This behaviorist approach either descriptively measures use of social media as a whole (e.g., frequency or duration) or collapses various social media uses into one broad, overall exposure measure (e.g., intensity), in both cases usually ignoring how or for what purposes social media are used.

\section{Social Media and Mental Health}

To connect our review on EWB to the larger research context, we first briefly summarize the current state of knowledge on social media's mental health effects in general, and then review theoretical and empirical links to three key EWB indicators, meaningfulness, authenticity, and self-actualization. We use the tripartite distinction of social media use as active, passive, and screen time to systematize the evidence. 


\section{Social Media and Mental Health: The State of the Field}

Numerous reviews (e.g., Appel et al., 2020; Meier \& Reinecke, 2020) and specification curve analyses of large datasets (Orben, 2020) have recently integrated the evidence on social media and mental health. In a particularly large overview, Meier and Reinecke (2020) synthesized the evidence from 34 systematic reviews and meta-analyses, which together included over 1,300 studies investigating the associations of CMC and social media with mental health. Given the danger of selective reporting in this field (cf. Twenge, 2019), we here summarize the main findings from these as well as more recent systematic reviews.

The meta-analytic evidence is largely limited to social media screen time, typically Facebook use, and mostly refers to young adults or adolescents. Various meta-analyses identified several small but consistent between-person correlations (see Meier \& Reinecke, 2020, for details): social media screen time was very weakly negatively associated with selfesteem; weakly positively associated with depressive symptoms, (social) anxiety symptoms, and stress; moderately positively associated with body image disturbance; and moderately positively associated with perceived social support/capital. Social media screen time was not consistently associated with life satisfaction or loneliness in the largest meta-analyses.

Overall, this pattern of results suggests that (young) individuals who spent more time on social media such as Facebook may experience slightly higher psychopathology and lower self-esteem but also higher perceived social resources. We emphasize that this evidence is overwhelmingly based on self-reports and refers to between-person correlations, not causation. Based on a recent systematic review (Course-Choi \& Hammond, 2021) and additional research, we also note that longitudinal panel studies to date find little to no evidence for positive or negative long-term effects of social media screen time on mental health in general (Orben et al., 2019; Schemer et al., 2020; but see Shakya \& Christakis, 
2017). However, some longitudinal evidence for negative effects on body image among adolescents exists (Course-Choi \& Hammond, 2021).

Another major takeaway from our (Meier \& Reinecke, 2020) as well as other reviews (e.g., Course-Choi \& Hammond, 2021; Verduyn et al., 2017) is that effect patterns become more complex if research distinguishes not just mental health outcomes but also the types of interactions and messages (i.e., different uses) that users engage with on social media. Specifically, several reviews conclude that active social media use is linked to better mental health, while passive use is linked to worse mental health (e.g., Course-Choi \& Hammond, 2021; Orben, 2020; Verduyn et al., 2017). Yet, more recent evidence suggests that this conclusion may be premature: a scoping review of studies published after 2017 finds that the effects of active and passive use on mental health are much more heterogeneous, with no clear picture emerging as of yet (Valkenburg, van Driel, \& Beyens, 2021).

In conclusion, based on the most recent and largest evidence reviews (Appel et al., 2020; Course-Choi \& Hammond, 2021; Meier \& Reinecke, 2020; Orben, 2020), concerns over strong negative mental health effects of social media appear to be overblown. Metaanalyses find several (very) small correlations of social media screen time with increased psychopathology (e.g., depressive symptoms), some increased risk (e.g., stress) and some decreased resilience factors (e.g., self-esteem) at the between-person level. However, metaanalytic evidence on affective well-being is largely missing and meta-analyses overall suggest no association with life satisfaction or loneliness (see Meier \& Reinecke, 2020, for details). More recent evidence, particularly large experience sampling studies investigating the withinperson level and studies distinguishing interactions and messages, however, suggest that social media's effects on affective well-being may be extremely heterogeneous and personspecific (see the research program by Valkenburg, Beyens, et al., 2021) as well as contentspecific (e.g., Meier, Gilbert, et al., 2020). Thus, social media's effects overall depend heavily on the individuals, types of social media use, and mental health indicators investigated. 
Finally, a noticeable gap in this literature is a lack of research on (a) potential positive effects of social media use beyond increased social resources and (b) effects on EWB (Meier $\&$ Reinecke, 2020). To advance research in this direction, we present the first narrative review of key social media uses (i.e., active, passive, and screen time) and three key EWB indicators: meaningfulness, authenticity, and self-actualization. We first briefly explicate each indicator and then review theoretical links and corresponding empirical evidence with active, passive, and screen time uses separately.

\section{Social Media on Eudaimonic Well-Being: Advancing the Field}

\section{Meaningfulness}

Meaningfulness is not only the "best proxy" for EWB (Huta, 2017, p. 22) but has also received considerable and increasing research interest in recent years (e.g., King et al., 2016; van Tongeren et al., 2018; Vohs et al., 2019). This literature, often chiefly concerned with global meaning in life, has converged on a tripartite definition of the concept. Meaningfulness is defined as the presence of purpose, significance (also termed mattering), and coherence (also termed comprehension) (King et al., 2016). While purpose refers to "one's sense of direction and goals in life", significance is defined as "perceptions of value, importance, or worth in various aspects of life", and coherence represents "people's experiences of making sense of the world around them" (van Tongeren et al., 2018, p. 96). Common sources of meaning are relationships, religious faith, high socioeconomic status, and experiences eliciting positive affect (King et al., 2016), but also challenging negative experiences (Tov \& Lee, 2016; Vohs et al., 2019). Intriguingly, large epidemiological studies find that meaning appears to be fairly present in most people's lives, not a luxury reserved for a select few (King et al., 2016). Given the links with social relationships and positive affect, it appears quite plausible that social media, which is used for relationship maintenance and entertainment by many, can be a source of meaning experiences in daily life. 
Active use. Active use may be linked to meaningfulness theoretically via the perceived quality and/or meaningfulness of mediated interactions. Social interaction with close others is generally perceived as a particularly meaningful and high-quality activity (e.g., Reis et al., 2000), which appears to be slightly more pronounced in face-to-face or voice communication versus text-based communication (e.g., Baym et al., 2004; Gonzales, 2014). Accordingly, social media companies are eager to increase "meaningful interaction" via their applications (Litt et al., 2020). Evidence on whether social media interactions contribute to meaningfulness is scarce, however. We only identified one large cross-cultural survey by Facebook researchers, which suggests that "in-person interactions can be just as meaningful as technology-mediated interactions" (Litt et al., 2020, p. 1). However, the meaningfulness of an interaction depended on whether it was with a strong tie (e.g., friends or family), happened synchronously, and in a planned and, ideally, memorialized fashion. We found no theoretical or empirical links between masspersonal active use (e.g., posting status updates) and meaningfulness.

Passive use. Passively processing others' activities on social media may show both negative (i.e., ostracism) and positive (i.e., inspiration) theoretical links to meaningfulness. Four experiments on social media ostracism suggest that seeing others interact online without joining in can induce a sense of meaningless existence (Lutz \& Schneider, 2020; Schneider et al., 2017; Wolf et al., 2015). In contrast, two experiments and two large cross-sectional surveys found that passively browsing typical social media content, such as travel and nature imagery or inspirational memes, can be perceived as meaningful (Meier, Gilbert, et al., 2020; Rieger \& Klimmt, 2019a, 2019b). This finding mirrors similar effects of typical eudaimonic entertainment fare, such as inspiring movies or YouTube clips (see Oliver \& Raney, this volume).

Screen time. As the first theoretical link, research from the screen time approach typically assumes "that most screen time is not 'meaningful' activity, and involves mainly 
ephemeral hedonic satisfactions or escape" (Rigby \& Ryan, 2017, p. 34). Indeed, one experiment suggests that even a short time spent on social media is perceived as a rather meaningless activity by users (Sagioglou \& Greitemeyer, 2014). While providing only indirect evidence, two surveys further indicate that enjoyment of and emotional dependence on Facebook is linked to lower purpose in life (Jung et al., 2017; Naeemi \& Tamam, 2017). No other evidence was found. A second theoretical link exists in the form of deficient selfregulation (e.g., procrastination). Successful self-regulation has been argued to be a key mechanism explaining meaning experiences (van Tongeren et al., 2018). Providing first indirect evidence, a diary study among students found that those with stronger mobile checking habits (including messenger checking) reported increased procrastination, which was linked to lower end-of-day meaningfulness (Meier, under review). A third theoretical link exists in negative self-conscious emotions (e.g., guilt, regret) around social media use (Reinecke \& Meier, 2020). Spending large amounts of time on social media may be perceived as a guilty and ultimately "meaningless" pleasure if it violates personal or societal norms about how much time is too much. We found no studies explicitly testing this, however.

\section{Authenticity}

Authenticity, the second key EWB indicator, is also receiving increased attention in psychology (e.g., Knoll et al., 2015; Smallenbroek et al., 2016; Sedikides et al., 2017). While there are several competing conceptualizations of authenticity, the definitions converge on “acting in accordance with core aspects of the self" (Smallenbroek et al., 2016, p. 197) or, more simply, being and expressing one's true self (Knoll et al., 2015; Sedikides et al., 2017). Knoll et al. (2015) further specify authenticity by differentiating the two components selfawareness (“know thyself”) and self-expression ("be thyself”). Expressing oneself in accordance with how one knows the self therefore signals authenticity. Studies observed that people feel authentic when they experience "fun, success, returning to familiar people or places, spending time with close others (i.e., hanging out), helping others, and being creative" 
(Sedikides et al., 2017, p. 522), all of which are possible via social media. In general, getting to know the self and expressing it accordingly may be afforded or constrained by social media, thus suggesting both positive and negative links to authenticity experiences.

Active use. We identify two theoretical links: First, people self-disclose more, and more deeply, in CMC due to higher autonomy over what, when, to whom, and how they can communicate (e.g., Luo \& Hancock, 2020). Due to these affordances of CMC, interpersonal social media use may lead to higher authenticity. This is supported by a diary study among students, which found autonomy in interpersonal social media use was linked to increased authenticity experiences (Meier, 2018). Other evidence is lacking, however. Second, masspersonal social media use may be linked to authenticity via positively biased public selfpresentation. Several studies have investigated this (for a review, see Twomey \& O'Reilly, 2017). Initial studies suggested that social media users only "put their best foot forward" when presenting themselves publicly, thus experiencing decreased authenticity due to public social media use. However, later studies found this "positivity bias" to be small: public social media self-presentations are predominantly positive, but still grounded in one's true self (see the review by Toma, 2017). Authentically sharing positive experiences has also been found to be more common on social media, and also more beneficial for affective well-being, than authentically sharing negative experiences (Reinecke \& Trepte, 2014). A recent review further suggests that authentic self-presentation on social media is related to other favorable mental health outcomes (Twomey \& O'Reilly, 2017). Evidence from a recent within-person study also suggests that both public feed posts and stories on Instagram are subjectively perceived as rather authentic (Kreling et al., 2021). Overall, there appears to be a strong, albeit complex empirical link between public social media use and authenticity self- as well as other-perceptions.

Passive use. Two theoretical mechanisms may link passive use to authenticity: First, several experiments show that passively viewing one's own social media profile can result in 
positive self-affirmation (for a review, see Toma, 2017). Such an effect could extend to increased self-awareness ("Who am I?"), but we note a lack of explicit evidence on this. Second, observing others' positively biased social media self-presentations has been studied extensively through the lens of social comparison (e.g., Meier, Gilbert, et al., 2020). Since social comparison is a key mechanism to gain insight about the self, it may impact authentic self-awareness, for better or worse. First indirect evidence for this comes from a short-term longitudinal study among emerging adults: comparing to others' abilities predicted lower identity clarity since unfavorable comparisons increased avoidance of processing identityrelated information (Yang et al., 2018). Social comparison on Facebook was also negatively associated with overall EWB in a cross-sectional survey (Gerson et al., 2016).

Screen time. Like meaningfulness, a first theoretical mechanism linking screen time to authenticity is that social media use somehow inherently lacks authentic experiential qualities. That is, users may perceive their time with the technology as an activity that, per se, “[does] not authentically advance eudaimonic living" and instead only provides "eudaimonic stagecraft" (Rigby \& Ryan, 2017, p. 46). We note a lack of direct evidence for this but observe much conjecture. For instance, a thematic analysis of digital detox texts (e.g., selfhelp literature) shows that losing touch with "real life" is a common theme in the current discourse on social media, suggesting that near-constant connectivity has created a "fascination for the authentic" (Syvertsen \& Enli, 2019, p. 1). A second theoretical link between screen time and authenticity exists in the form of reduced self-concept clarity, which is related to the self-awareness component of authenticity. Early studies on adolescents' found mixed results on the role of online communication for self-concept clarity (see the review by Valkenburg \& Peter, 2011). However, two recent cross-sectional surveys and a two-wave panel study by Appel et al. (2018) indeed found that more intense Facebook use was (longitudinally) related to decreased self-concept clarity, lending some support for this link. 


\section{Self-Actualization}

While authenticity includes knowing one's true self and expressing it, selfactualization can be described as becoming one's true self - that is, becoming more authentic over time and developing the best in oneself (e.g., Ryff, 1989; Waterman, 2008). Selfactualization is the most common definition of eudaimonia among PWB scholars (Huta \& Waterman, 2014). Yet, compared to meaningfulness and authenticity, it has received notably less research attention. The best-known operationalization is the personal growth facet in Ryff's (1989) well-being scale, which aims to measure whether "one continue[s] to develop one's potential, to grow and expand as a person" (p. 1071). Research generally shows that "progressing through the developmental tasks of adult life" (Ryff, 2014, p. 14) is linked to

personal growth. Moreover, being less neurotic and more open to experiences has been metaanalytically linked to self-reported personal growth (Anglim et al., 2020). Thus, if social media use is relevant for developmental tasks, such as identity exploration, or confronts users with new experiences that challenge their identity, it may show (long-term) effects on selfactualization.

Active use. While we are unaware of theoretical or empirical links between interpersonal social media use and self-actualization, masspersonal social media use may be linked via so-called "identity shift" (Gonzales \& Hancock, 2008). As argued above, public self-presentation on social media may feed back into how one perceives the self (i.e., authentic self-awareness) and how one presents the self subsequently (i.e., authentic selfexpression). Since self-actualization can be understood as becoming more authentic over time, and provided that public social media self-presentations impact short-term authenticity, masspersonal use could also have more long-term consequences for self-actualization. While lending only indirect support, several experiments on "identity shift" in CMC suggest that due to public commitment, how one presents the self in front of an audience (e.g., as introvert or extravert) can lead to an internalization of that presentation and thus short-term changes in 
self-perception (e.g., Carr, 2020; Gonzales \& Hancock, 2008; Walther et al., 2011). Coupled with evidence on identity exploration on social media, especially among adolescents (see Jordan, 2018, for a review), such identity shifts could, over time, impact self-actualization. Yet, we found no evidence for or against this link.

Passive use. A theoretical link between passive processing of social media posts and self-actualization exists in the form of eudaimonic entertainment experiences. Eudaimonic content, such as stories that confront users with human challenges and how they can be overcome, is common in traditional entertainment media, but also on social media (see Oliver \& Raney, this volume). Research on the cognitive and affective "challenges" posed by media content further argues that if such content is sought out and appreciated, it should contribute to personal growth (Bartsch \& Hartmann, 2017). While initial research has investigated eudaimonic content on social media (e.g. Rieger \& Klimmt, 2019a, 2019b), we found no direct evidence on passive social media use and self-actualization.

Screen time. A theoretical link between social media screen time and selfactualizations exists in the classic displacement hypothesis. This mechanism assumes that time on social media leads to either the short-term postponement or long-term replacement of activities deemed more beneficial for long-term personal development, such as face-to-face interaction, physical activity, studying, or work (e.g., Twenge, 2019). One might assume that negative short-term displacement effects of social media use could accumulate over time, thus stopping users' from realizing their true selves. We are unaware of studies investigating this explicitly. However, a diary study testing the effects of social media abstinence found that when not using social media, participants spent more time on rather mundane activities (e.g., cooking/cleaning), but also on work (Hall et al., 2019), lending some support for short-term displacement effects. Providing additional indirect evidence, two cross-sectional surveys further observed that if Facebook was used more intensely (Naeemi \& Tamam, 2017) or for enjoyment (Jung et al., 2017), this was related to lower personal growth. Whether such an 
effect extends to reduced long-term self-actualization, specifically given the potentially multifacetted short-term effects discussed above for authenticity, remains an open question.

\section{Discussion and Future Directions}

The present narrative review contributes to our understanding of social media's mental health impacts, firstly, by summarizing the state of the field and, secondly, by carving out and integrating potential effects on the so far often neglected eudaimonic side of well-being. Correlational evidence on social media and hedonic well-being, psychopathology, and psychosocial risk/resilience factors is extensive, yet currently suggests that social media play a minor role for users' mental health on average. The evidence, however, also suggests that when some individuals (e.g., vulnerable adolescents) engage in some specific uses (e.g., viewing idealized body- or fitness-related social media posts) this can sometimes result in negative effects on some indicators (e.g., body image disturbance). Accordingly, while there is no positive or negative "one-size-fits-all" effect, social media may occasionally impact some aspects of mental health for some users. Among other implications, these findings underline the need to carefully consider the mental health indicators that are (not) investigated. Given the danger of outcome omission bias in this field, we believe it prudent to investigate mental health as comprehensively as possible.

We thus reviewed the effects of social media on EWB. The review shows that studies on social media and EWB are particularly scarce and currently provide weak and mostly indirect evidence for positive or negative effects on meaning, authenticity, and selfactualization. While there are a few disconnected initial studies, the evidence is too limited to allow a definite answer to the question whether social media affect EWB. This is in stark contrast to public concern over social media's mental health impacts, which often centers on social media somehow reducing meaning, authenticity, and self-actualization, thus taking away from "the good life" (see, e.g., the digital detox discourse analyzed by Syvertsen \& Enli, 2019). The present review therefore suggests future research can close an important gap by 
empirically testing whether these concerns have any basis (cf. Rigby \& Ryan, 2017; Twenge, 2019). Moreover, this review provides key impulses for the field by highlighting unexplored theoretical links between EWB and active versus passive social media use as well as the overall engagement with social media.

Based on this review, we can derive four key recommendations for how research should proceed. First, (1) our review of the well-being literature suggests that social media effects research should include both HWB and EWB indicators, since they exhibit conceptual and empirical distinctness. This is particularly important to uncover potentially differential effect patterns of social media use on affect versus the eudaimonic concepts reviewed here. Most importantly, (2) the field requires studies that relate interactions and messages on social media (see Meier \& Reinecke, 2020) to meaning, authenticity, and self-actualization with designs that (3) vary timeframes and, ideally, allow causal conclusions. Finally, (4) our review found that most existing studies investigated the three EWB concepts within social media contexts (e.g., meaningful interactions or authentic self-presentations on Facebook). To allow for more rigorous conclusions about effects, studies should instead test whether social media use (e.g., interactions or posts on Facebook) changes EWB outside of the technological context (e.g., meaning in life, authenticity).

In conclusion, while most existing studies focus on whether social media makes users feel better or worse (Meier \& Reinecke, 2020), research will provide more compelling answers to public concerns by simultaneously investigating whether social media make users $d o$ better or worse, especially in the long run (see Martela \& Sheldon, 2019, for an extended discussion of this distinction). Most intriguingly, even if social media may occasionally confront users with challenging, negative emotional experiences, from a eudaimonic perspective these can represent opportunities to find meaning, gain insight, live authentically, and grow as a person. Whether, how, and when social media users can overcome the emotional challenges of social media to their benefit remains a key question for the field. 


\section{References}

Studies included in the narrative review, that is, those providing direct or indirect evidence on social media and eudaimonic well-being, are marked with an asterisk (*). Abe, J. A. A. (2016). A longitudinal follow-up study of happiness and meaning-making. The Journal of Positive Psychology, 11(5), 489-498. https://doi.org/10.1080/17439760.2015.1117129

Anglim, J., Horwood, S., Smillie, L. D., Marrero, R. J., \& Wood, J. K. (2020). Predicting psychological and subjective well-being from personality: A meta-analysis. Psychological Bulletin, 146(4), 279-323. https://doi.org/10.1037/bu10000226

Appel, M., Marker, C., \& Gnambs, T. (2020). Are social media ruining our lives? A review of meta-analytic evidence. Review of General Psychology, 24(1), 60-74. https://doi.org/10.1177/1089268019880891

*Appel, M., Schreiner, C., Weber, S., Mara, M., \& Gnambs, T. (2018). Intensity of Facebook use is associated with lower self-concept clarity. Journal of Media Psychology, 30(3), 160172. https://doi.org/10.1027/1864-1105/a000192

Bartsch, A., \& Hartmann, T. (2017). The role of cognitive and affective challenge in entertainment experience. Communication Research, 44(1), 29-53. https://doi.org/10.1177/0093650214565921

Bayer, J. B., Triệu, P., \& Ellison, N. B. (2020). Social media elements, ecologies and effects. Annual Review of Psychology, 71, 10.1-10.27. https://doi.org/10.1146/annurev-psych010419-050944

*Baym, N. K., Zhang, Y. B., \& Lin, M.-C. (2004). Social interactions across media: Interpersonal communication on the Internet, telephone and face-to-face. New Media \& Society, 6(3), 299-318. https://doi.org/10.1177/1461444804041438 
Berrios, R., Totterdell, P., \& Kellett, S. (2018). When feeling mixed can be meaningful: The relation between mixed emotions and eudaimonic well-being. Journal of Happiness Studies, 19(3), 841-861. https://doi.org/10.1007/s10902-017-9849-y

Burns, R. A., \& Ma, J. (2015). Examining the association between psychological wellbeing with daily and intra-individual variation in subjective wellbeing. Personality and Individual Differences, 82, 34-39. https://doi.org/10.1016/j.paid.2015.02.023

*Carr, C. T. (2020). Identity shift effects of personalization of self-presentation on extraversion. Media Psychology. Advance online publication. https://doi.org/10.1080/15213269.2020.1753540

Course-Choi, J., \& Hammond, L. (2021). Social media use and adolescent well-being: A narrative review of longitudinal studies. Cyberpsychology, Behavior, and Social Networking, 24(4), 223-236. https://doi.org/10.1089/cyber.2020.0020

Cowan, H. R. (2019). Can a good life be unsatisfying? Within-person dynamics of life satisfaction and psychological well-being in late midlife. Psychological Science, 30(5), 697-710. https://doi.org/10.1177/0956797619831981

Crisp, R. (2013). Well-being. In E. N. Zalta (Ed.), The Stanford encyclopedia of philosophy. https://plato.stanford.edu/archives/fall2017/entries/well-being/

Diener, E. (1984). Subjective well-being. Psychological Bulletin, 95(3), 542-575. https://doi.org/10.1037/0033-2909.95.3.542

Diener, E., Lucas, R. E., \& Oishi, S. (2018). Advances and open questions in the science of subjective well-being. Collabra: Psychology, 4(1), 1-49. https://doi.org/10.1525/collabra.115

*Gerson, J., Plagnol, A. C., \& Corr, P. J. (2016). Subjective well-being and social media use: Do personality traits moderate the impact of social comparison on Facebook? Computers in Human Behavior, 63, 813-822. https://doi.org/10.1016/j.chb.2016.06.023 
*Gonzales, A. L. (2014). Text-based communication influences self-esteem more than faceto-face or cellphone communication. Computers in Human Behavior, 39, 197-203. https://doi.org/10.1016/j.chb.2014.07.026

*Gonzales, A. L., \& Hancock, J. T. (2008). Identity shift in computer-mediated environments. Media Psychology, 11(2), 167-185. https://doi.org/10.1080/15213260802023433

*Hall, J. A., Johnson, R. M., \& Ross, E. M. (2019). Where does the time go? An experimental test of what social media displaces and displaced activities' associations with affective well-being and quality of day. New Media \& Society, 21(3), 674-692. https://doi.org/10.1177/1461444818804775

Hofmann, W., Reinecke, L., \& Meier, A. (2017). Of sweet temptations and bitter aftertaste: Self-control as a moderator of the effects of media use on well-being. In L. Reinecke \& M. B. Oliver (Eds.), The Routledge handbook of media use and well-being: International perspectives on theory and research on positive media effects (pp. 211-222). Routledge.

Huta, V. (2017). An overview of hedonic and eudaimonic well-being concepts. In L. Reinecke \& M. B. Oliver (Eds.), The Routledge handbook of media use and well-being: International perspectives on theory and research on positive media effects (pp. 14-33). Routledge.

Huta, V., \& Waterman, A. S. (2014). Eudaimonia and its distinction from hedonia: Developing a classification and terminology for understanding conceptual and operational definitions. Journal of Happiness Studies, 15(6), 1425-1456. https://doi.org/10.1007/s10902-013-9485-0

Jordan, A. (2018). Growing up online: Media use and development in early adolescence. In P. Vorderer, D. Hefner, L. Reinecke, \& C. Klimmt (Eds.), Permanently online, permanently connected: Living and communication in a POPC world (pp. 165-175). Routledge. 
*Jung, Y., Pawlowski, S. D., \& Kim, H.-W. (2017). Exploring associations between young adults' facebook use and psychological well-being: A goal hierarchy approach. International Journal of Information Management, 37(1), 1391-1404. https://doi.org/10.1016/j.ijinfomgt.2016.10.005

Kashdan, T. B., Biswas-Diener, R., \& King, L. A [Laura A.] (2008). Reconsidering happiness: the costs of distinguishing between hedonics and eudaimonia. The Journal of Positive Psychology, 3(4), 219-233. https://doi.org/10.1080/17439760802303044

King, L. A [L. A.], Heintzelman, S. J., \& Ward, S. J. (2016). Beyond the search for meaning: A contemporary science of the experience of meaning in life. Current Directions in Psychological Science, 25(4), 211-216. https://doi.org/10.1177/0963721416656354

Knoll, M., Meyer, B., Kroemer, N. B., \& Schröder-Abé, M. (2015). It takes two to be yourself: An integrated model of authenticity, its measurement, and its relationship to work-related variables. Journal of Individual Differences, 36(1), 38-53. https://doi.org/10.1027/1614-0001/a000153

*Kreling, R., Meier, A., \& Reinecke, L. (2021). Feeling authentic on social media: Subjective authenticity across Instagram Stories and Posts. PsyArXiv. https://doi.org/10.31234/osf.io/jz3wm

Lahey, B. B., Krueger, R. F., Rathouz, P. J., Waldman, I. D., \& Zald, D. H. (2017). A hierarchical causal taxonomy of psychopathology across the life span. Psychological Bulletin, 143(2), 142-186. https://doi.org/10.1037/bul0000069

*Litt, E., Zhao, S., Kraut, R., \& Burke, M. (2020). What are meaningful social interactions in today's media landscape? A cross-cultural survey. Social Media + Society. Advance online publication. https://doi.org/10.1177/2056305120942888 
Luo, M., \& Hancock, J. T. (2020). Self-disclosure and social media: Motivations, mechanisms and psychological well-being. Current Opinion in Psychology, 31, 110-115. https://doi.org/10.1016/j.copsyc.2019.08.019

*Lutz, S., \& Schneider, F. M. (2020). Is receiving dislikes in social media still better than being ignored? The effects of ostracism and rejection on need threat and coping responses online. Media Psychology, 1-25. https://doi.org/10.1080/15213269.2020.1799409

Martela, F., \& Sheldon, K. M. (2019). Clarifying the concept of well-being: Psychological need satisfaction as the common core connecting eudaimonic and subjective well-being. Review of General Psychology, 23(4), 458-474.

https://doi.org/10.1177/1089268019880886

*Meier, A. (under review). Studying problems, not problematic usage: Do mobile checking habits increase procrastination and decrease well-being? Mobile Media \& Communication.

*Meier, A. (2018). Alles eine Frage der digitalen Autonomie? Die Rolle von Autonomie in der digitalen Kommunikation für psychologische Grundbedürfnisse und psychische Gesundheit im Alltag [Digital autonomy is key? The role of autonomy in online communication for need satisfaction and psychological well-being in daily life]. Medien \& Kommunikationswissenschaft, 66(4), 407-427. https://doi.org/10.5771/1615-634X-2018-4407

Meier, A., Domahidi, E., \& Günther, E. (2020). Computer-mediated communication and mental health: A computational scoping review of an interdisciplinary field. In S. Yates \& R. E. Rice (Eds.), The Oxford handbook of digital technology and society (pp. 79-110). Oxford Univ. Press. https://doi.org/10.1093/oxfordhb/9780190932596.013.4

*Meier, A., Gilbert, A., Börner, S., \& Possler, D. (2020). Instagram inspiration: How upward comparison on social network sites can contribute to well-being. Journal of Communication, 70(5), 721-743. https://doi.org/10.1093/joc/jqaa025 
Meier, A., \& Reinecke, L. (2020). Computer-mediated communication, social media, and mental health: A conceptual and empirical meta-review. Communication Research. Advance online publication. https://doi.org/10.1177/0093650220958224

*Naeemi, S., \& Tamam, E. (2017). The relationship between emotional dependence on Facebook and psychological well-being in adolescents aged 13-16. Child Indicators Research, 10(4), 1095-1106. https://doi.org/10.1007/s12187-016-9438-3

O’Sullivan, P. B., \& Carr, C. T. (2018). Masspersonal communication: A model bridging the mass-interpersonal divide. New Media \& Society, 20(3), 1161-1180. https://doi.org/10.1177/1461444816686104

Orben, A. (2020). Teenagers, screens and social media: A narrative review of reviews and key studies. Social Psychiatry and Psychiatric Epidemiology, 55, 407-414. https://doi.org/10.1007/s00127-019-01825-4

Orben, A., Dienlin, T., \& Przybylski, A. K. (2019). Social media's enduring effect on adolescent life satisfaction. Proceedings of the National Academy of Sciences of the United States of America, 116(21), 10226-10228. https://doi.org/10.1073/pnas.1902058116

Reinecke, L., \& Meier, A. (2020). Guilt and media use. In J. van den Bulck (Ed.), The international encyclopedia of media psychology. Wiley-Blackwell. https://doi.org/10.1002/9781119011071.iemp0183

*Reinecke, L., \& Trepte, S. (2014). Authenticity and well-being on social network sites: A two-wave longitudinal study on the effects of online authenticity and the positivity bias in SNS communication. Computers in Human Behavior, 30, 95-102. https://doi.org/10.1016/j.chb.2013.07.030

Reis, H. T., Sheldon, K. M., Gable, S. L., Roscoe, J., \& Ryan, R. M. (2000). Daily well-being: The role of autonomy, competence, and relatedness. Personality and Social Psychology Bulletin, 26(4), 419-435. https://doi.org/10.1177/0146167200266002 
*Rieger, D., \& Klimmt, C. (2019a). The daily dose of digital inspiration: A multi-method exploration of meaningful communication in social media. New Media \& Society, 21(1), 97-118. https://doi.org/10.1177/1461444818788323

*Rieger, D., \& Klimmt, C. (2019b). The daily dose of digital inspiration 2: Themes and affective user responses to meaningful memes in social media. New Media \& Society. Advance online publication. https://doi.org/10.1177/1461444819842875

Rigby, C. S., \& Ryan, R. M. (2017). Time well-spent? Motivation for entertainment media and its eudaimonic aspects through the lens of self-determination theory. In L. Reinecke \& M. B. Oliver (Eds.), The Routledge handbook of media use and well-being: International perspectives on theory and research on positive media effects (pp. 34-48). Routledge.

Ryan, R. M., \& Deci, E. L. (2001). On happiness and human potentials: A review of research on hedonic and eudaimonic well-being. Annual Review of Psychology, 52(1), 141-166. https://doi.org/10.1146/annurev.psych.52.1.141

Ryff, C. D. (1989). Happiness is everything, or is it? Explorations on the meaning of psychological well-being. Journal of Personality and Social Psychology, 57(6), 10691081. https://doi.org/10.1037/0022-3514.57.6.1069

Ryff, C. D. (2014). Psychological well-being revisited: Advances in the science and practice of eudaimonia. Psychotherapy and Psychosomatics, 83(1), 10-28. https://doi.org/10.1159/000353263

*Sagioglou, C., \& Greitemeyer, T. (2014). Facebook's emotional consequences: Why Facebook causes a decrease in mood and why people still use it. Computers in Human Behavior, 35, 359-363. https://doi.org/10.1016/j.chb.2014.03.003

Schemer, C., Masur, P. K., Geiß, S., Müller, P., \& Schäfer, S. (2020). The impact of Internet and social media use on well-being: A longitudinal analysis of adolescents across nine 
years. Journal of Computer-Mediated Communication. Advance online publication. https://doi.org/10.1093/jcmc/zmaa014

*Schneider, F. M., Zwillich, B., Bindl, M. J., Hopp, F. R., Reich, S., \& Vorderer, P. (2017). Social media ostracism: The effects of being excluded online. Computers in Human Behavior, 73, 385-393. https://doi.org/10.1016/j.chb.2017.03.052

Sedikides, C., Slabu, L., Lenton, A., \& Thomaes, S. (2017). State authenticity. Current Directions in Psychological Science, 26(6), 521-525. https://doi.org/10.1177/0963721417713296

Shakya, H. B., \& Christakis, N. A. (2017). Association of Facebook use with compromised well-being: A longitudinal study. American Journal of Epidemiology, 185(3), 203-211. https://doi.org/10.1093/aje/kww189

Smallenbroek, O., Zelenski, J. M., \& Whelan, D. C. (2016). Authenticity as a eudaimonic construct: The relationships among authenticity, values, and valence. The Journal of Positive Psychology, 12(2), 197-209. https://doi.org/10.1080/17439760.2016.1187198

Syvertsen, T., \& Enli, G. (2019). Digital detox: Media resistance and the promise of authenticity. Convergence: The International Journal of Research into New Media Technologies. Advance online publication. https://doi.org/10.1177/1354856519847325

*Toma, C. L. (2017). Taking the good with the bad: Effects of Facebook self-presentation on emotional well-being. In L. Reinecke \& M. B. Oliver (Eds.), The Routledge handbook of media use and well-being: International perspectives on theory and research on positive media effects (pp. 170-182). Routledge.

Tov, W., \& Lee, H. W. (2016). A closer look at the hedonics of everyday meaning and satisfaction. Journal of Personality and Social Psychology, 111(4), 585-609. https://doi.org/10.1037/pspp0000081 
Trifiro, B. M., \& Gerson, J. (2019). Social media usage patterns: Research note regarding the lack of universal validated measures for active and passive use. Social Media + Society, 5(2), 205630511984874. https://doi.org/10.1177/2056305119848743

Twenge, J. M. (2019). More time on technology, less happiness? Associations between digital-media use and psychological well-being. Current Directions in Psychological Science, 28(4), 372-379. https://doi.org/10.1177/0963721419838244

*Twomey, C., \& O'Reilly, G. (2017). Associations of self-presentation on Facebook with mental health and personality variables: A systematic review. Cyberpsychology, Behavior, and Social Networking, 20(10), 587-595. https://doi.org/10.1089/cyber.2017.0247

Valkenburg, P. M., Beyens, I., Pouwels, J. L., van Driel, I. I [Irene I.], \& Keijsers, L. (2021). Social media use and adolescents' self-esteem: Heading for a person-specific media effects paradigm. Journal of Communication, 71(1), 56-78. https://doi.org/10.1093/joc/jqaa039

*Valkenburg, P. M., \& Peter, J. (2011). Online communication among adolescents: An integrated model of its attraction, opportunities, and risks. Journal of Adolescent Health, 48(2), 121-127. https://doi.org/10.1016/j.jadohealth.2010.08.020

Valkenburg, P. M., van Driel, I. I [Irene Ingeborg], \& Beyens, I. (2021). Social media and well-being: Time to abandon the active-passive dichotomy. https://doi.org/10.31234/osf.io/j6xqz

van Tongeren, D. R., DeWall, C. N., Green, J. D., Cairo, A. H., Davis, D. E., \& Hook, J. N. (2018). Self-regulation facilitates meaning in life. Review of General Psychology, 22(1), 95-106. https://doi.org/10.1037/gpr0000121

Verduyn, P., Ybarra, O., Résibois, M., Jonides, J., \& Kross, E. (2017). Do social network sites enhance or undermine subjective well-being? A critical review. Social Issues and Policy Review, 11(1), 274-302. https://doi.org/10.1111/sipr.12033 
Vohs, K. D., Aaker, J. L., \& Catapano, R. (2019). It's not going to be that fun: Negative experiences can add meaning to life. Current Opinion in Psychology, 26, 11-14. https://doi.org/10.1016/j.copsyc.2018.04.014

*Walther, J. B., Liang, Y. J., DeAndrea, D. C., Tong, S. T., Carr, C. T., Spottswood, E. L., \& Amichai-Hamburger, Y. (2011). The effect of feedback on identity shift in computermediated communication. Media Psychology, 14(1), 1-26. https://doi.org/10.1080/15213269.2010.547832

Waterman, A. S. (2008). Reconsidering happiness: A eudaimonist's perspective. The Journal of Positive Psychology, 3(4), 234-252. https://doi.org/10.1080/17439760802303002

*Wolf, W., Levordashka, A., Ruff, J. R., Kraaijeveld, S., Lueckmann, J.-M., \& Williams, K. D. (2015). Ostracism Online: A social media ostracism paradigm. Behavior Research Methods, 47(2), 361-373. https://doi.org/10.3758/s13428-014-0475-X

World Health Organization. (2005). Promoting mental health: Concepts, emerging evidence, practice. http://www.who.int/mental_health/evidence/MH_Promotion_Book.pdf

*Yang, C.-C., Holden, S. M., \& Carter, M. D. K. (2018). Social media social comparison of ability (but not opinion) predicts lower identity clarity: Identity processing style as a mediator. Journal of Youth and Adolescence, 47(10), 2114-2128.

https://doi.org/10.1007/s10964-017-0801-6 